\title{
Strategy instruction in listening for lower- intermediate learners of French
}

Article

Accepted Version

Graham, S. J. and Macaro, E. (2008) Strategy instruction in listening for lower-intermediate learners of French. Language Learning, 58 (4). pp. 747-783. ISSN 0023-8333 doi:

https://doi.org/10.1111/j.1467-9922.2008.00478.x Available at https://centaur.reading.ac.uk/7993/

It is advisable to refer to the publisher's version if you intend to cite from the work. See Guidance on citing.

To link to this article DOI: http://dx.doi.org/10.1111/j.1467-9922.2008.00478.x

Publisher: Wiley

All outputs in CentAUR are protected by Intellectual Property Rights law, including copyright law. Copyright and IPR is retained by the creators or other copyright holders. Terms and conditions for use of this material are defined in the End User Agreement.

\section{www.reading.ac.uk/centaur}

\section{CentAUR}

Central Archive at the University of Reading

Reading's research outputs online 
Strategy instruction in listening for lower-intermediate learners of French.

\author{
Suzanne Graham \\ University of Reading \\ Ernesto Macaro \\ University of Oxford
}

Correspondence concerning this article should be addressed to Suzanne Graham,

Institute of Education, The University of Reading, Bulmershe Court, Earley, Reading, UK, RG6 1HY.E-mail: s.j.graham@ reading.ac.uk 


\begin{abstract}
L2 listening has historically proved to be a difficult skill. Strategy instruction studies have sought to bring about improvements in subjects' listening but with mixed results. This lack of success may be due to the nature of listening strategy theory and its influence on conceptualizations of listening strategy instruction. The current study, based on an initial descriptive investigation of a specific population of learners, measured the effects of strategy instruction on both the listening performance and self-efficacy of 68 lower-intermediate learners of French in England, against a comparison group. Moreover, the effects of high- and low-scaffolded interventions were compared. Results suggest that the programme improved listening proficiency and learners' confidence about listening. Implications for pedagogy and strategy theory are discussed.
\end{abstract}


Strategy instruction in listening for lower-intermediate learners of French.

The challenges that listening comprehension in the second language (L2) pose for learners have long been highlighted (e.g. Anderson \& Lynch, 1988; Richards, 1983). There is evidence that it induces anxiety in learners, because of the pressure it places on them to process input rapidly (Arnold, 2000). Graham (2002, 2006), investigating the lack of popularity of foreign language learning in England, found that for lowerintermediate learners listening was not only the skill in which they experienced the greatest difficulty, but also the skill they felt was most difficult to improve. It therefore seems pertinent to examine approaches that might enhance listening comprehension.

In this introduction we attempt to link together theories pertaining to the general processes involved in listening to theories which have emerged about the strategies that listeners deploy in order to comprehend spoken text. These in turn are examined for the influence they have had on strategy instruction theory and practice.

\section{Theories of Listening Processes}

It is perhaps unsurprising that learners perceive listening as difficult, given the complexity and rapidity of the processes involved. Several theories have been advanced to account for these processes, with two being particularly influential on research. Although these two theories appear complementary they may in fact conflict, as we hope to show. 
The first theory is that of J.R. Anderson $(1983,1995)$, who proposed a cognitive framework that presents listening as a three-stage process, beginning with perceptual processing. Here attention is focused entirely on the text, phonemes are segmented from the speech stream, and these are then held in echoic memory (Anderson, 1995, p. 137). In the second stage, parsing, meaningful mental representations are formed from words and phrases by matching them with linguistic information stored in long-term memory. In the last phase, utilization, information collected in the previous two phases is related to the listener's schemata (see below). While this model of listening has the advantage of providing recognizable stages in the process of listening, thereby facilitating research into each of those stages (as in O’Malley, Chamot \& Küpper, 1989), it seems also to have disadvantages, chiefly because it presents listening as a linear process with utilization as the final product of those processes. As we shall see from our own (phase 1) research, it is perfectly possible for listeners to start by utilizing fragments of parsed text and then draw incorrect inferences. A more convincing model would be a recursive one, with listeners operating within more than one phase at a time thanks to the parallel processing capacity (McClelland \& Rumelhart, 1986) offered by working memory.

A more convincing model is one of interactive top-down and bottom-up processing. In top-down processing, the listener's background knowledge (of the topic, general world knowledge, and of how texts 'work'), interacts with the linguistic knowledge drawn upon in bottom-up processing to create an interpretation of the text (Buck, 2001, p. 29). In other words, the listener comes to a listening task with two sets of resources: his/her own linguistic and schematic knowledge (Rumelhart, 1980), and the information, both ideational and textual, contained in the actual listening text. Within an interactive model, a listener might begin by activating his/her schemata as a 
result of knowing the topic of the text, or of understanding a few words of the text, and virtually simultaneously 'perceive' and 'parse' the incoming speech stream, matching it (or mismatching it) with the elaborations previously activated.

The respective contribution of linguistic and non-linguistic knowledge to effective listening is still not clearly understood (Tsui \& Fullilove, 1998), although there is general consensus that listening requires a combination of both forms. Field (2004), commenting on the work of Stanovich (1980) in reading, argued that in both listening and reading, an "interactive-compensatory mechanism" (Field, 2004, p. 367) comes into play, whereby deficits or problems in either linguistic or non-linguistic sources of knowledge lead the listener or reader to turn to the other source of knowledge to compensate for these shortcomings. Whilst we would concur that the two sets of resources can indeed operate in a compensatory manner when comprehension problems occur, they may also act in a confirmatory manner when listening is relatively problem-free. Thus the interaction of top-down and bottom-up processes is likely to be both compensatory and confirmatory.

\section{Theories of Strategic Behavior in Listening}

Elements of the theoretical perspectives outlined above have been drawn on in research that has investigated listening comprehension from the point of view of the cognitive and metacognitive strategies employed by listeners (e.g. O’Malley et al, 1989). The literature does not provide us with one undisputed definition of learner strategies, but in one of the most recent reviews, Macaro (2006) argued that essential features of a strategy are conscious mental activity, employed in pursuit of a goal within a learning situation, and "transferable to other situations or tasks" (p. 328) . 
Although the strategy elicitation literature has explored both bottom-up and top-down strategies, one result of the Anderson model has been that greater emphasis has been placed on the facilitating nature of strategies involving top-down processing (such as inferring). Indeed, a number of authors of such studies have concluded that bottom-up strategies such as 'translating' (thinking about the L1 meaning of an L2 word) are the mark of ineffective listeners (Chien \& Wei, 1998; O’Malley et al., 1989; Vandergrift, 1998).

A recent review of research into listening strategies (Macaro, Graham \& Vanderplank, 2007 ) identifies the strategies that have consistently been advocated as playing an important part in the listening process, namely:

1. making predictions about the likely content of a passage (e.g. Goh, 1998);

2. selectively attending to certain aspects of the passage, deciding to 'listen out for' particular words or phrases or idea units (e.g. O’Malley et al., 1989);

3. monitoring and evaluating comprehension, i.e. checking that one is in fact understanding or has made the correct interpretation (e.g. Goh, 2002: Vandergrift, 2003; Young, 1996) and

4. using a variety of clues (linguistic, contextual and background knowledge) to infer the meaning of unknown words (e.g. Goh, 2002).

As a cluster of interacting strategies the above could, hypothetically, be operating as follows: Prediction stimulates schemata and simultaneously lightens the cognitive load by reducing the total number of possible propositions to consider. Listening out for certain ideas, words or phrases confirms or disconfirms predictions. When those ideas or phrases present comprehension problems, linguistic, contextual and prior knowledge of the topic compensate for lack of linguistic knowledge thereby facilitating inference. Monitoring and evaluating comprehension ensure that all these 
cognitive strategies are working in harmony. Indeed, the importance of metacognitive strategies that regulate the listening process has been increasingly emphasized (e.g. Vandergrift, 2003). It has been argued that this metacognitive control over strategy use by the listener is an essential aspect of long-term listening development and indeed of learner independence (Wenden, 1998).

However, in spite of this increased emphasis on the importance of a controlled orchestration of a cluster of strategies (N.J. Anderson, 1991), many studies continue to emphasize instead the importance of individual strategies, and particularly topdown strategies. For example, in a study of the listening difficulties experienced by Arabic students of English, Hasan (2000) interpreted students' problems with perception features such as speed of delivery and unclear speech as an indication that they required more training in top-down strategies that would allow them to compensate for their bottom-up weaknesses. Similarly, while Vandergrift (1998) acknowledged that limited linguistic knowledge may be an important factor in ineffective listening, he also argued that limited linguistic knowledge can be overcome by extra-linguistic contextual clues and other strategies to "instantiate a schema" (Vandergrift, 1998, p.391). In other words, when strategies are promoted in isolation rather than in clusters, there is a failure to acknowledge the potential for their misuse, particularly the misuse of prior knowledge when inferencing unfamiliar words, as a number of authors have demonstrated (e.g. Macaro, Vanderplank \& Graham, 2005; Tsui \& Fullilove 1998; see also our Phase 1 findings below ). 
An emphasis on top-down strategies has contributed to the notion of the existence of a universal successful listener as one who, regardless of general proficiency and linguistic knowledge, skips over textual difficulties by deploying compensatory schematic knowledge. This notion co-exists with the widespread belief in the strategies literature (Naiman, Fröhlich, Stern \& Todesco, 1978; Rubin, 1975; Takeuchi, 2003) that by studying successful learners we can then teach less successful learners more effective strategic behavior. However, research that suggests that successful and less successful learners use very similar strategies but in less effective combinations (e.g. Graham, 1997; Vann \& Abraham, 1990) questions this approach and, as Kojic-Sabo and Lightbown (1999, p.177) argue, undermines the "stereotypical dichotomous categorization of good versus poor learners" based on strategy use. Furthermore, whether successful learners use certain strategies because they have reached a higher level of proficiency or whether the use of those strategies has led to that higher level of proficiency is still contested (see for example Macaro et al., 2007). With these caveats in mind, the approach taken in the strategy instruction in this study was to start with specific group-type needs together with individual listeners' specific needs as related to their level of linguistic knowledge, the various tasks at hand, and their current strategic behavior (see below for further details of the instructional approach). This stands in contrast to most previous listening strategy instruction studies, few of which have focused on the specific needs of groups of learners or individual learners at a particular proficiency level. Of six studies identified, only one (Ozeki, 2000) based the selection of strategies taught on any kind of needs analysis. In Phase 1 of Ozeki's study, the researcher established which strategies a group of 45 junior college Japanese EFL learners did not use and incorporated them into the subsequent training. However, this approach still implicitly 
adopts a belief that there are strategies that 'successful listeners' use and that the function of instruction is to teach these to 'poor' listeners. Similarly, Thomson and Rubin (1996) based the strategies selected for instruction on those reported by successful listeners, as did Seo (2000), although in this latter study a pre-instruction phase did identify the strategies used by a group of learners similar to those involved in the instruction phase.

In a number of other intervention studies, strategy selection has been justified by recourse to various theoretical perspectives, namely Schema and Relevance Theory (McGruddy, 1995), theories of metacognition (Kohler, 2002), and findings from L1 strategy instruction research (O’Malley, Chamot, Stewner-Manzanares, Russo \& Küpper, 1985). There is thus little consensus as to what principles should guide the creation of a listening strategies instruction programme.

\section{Results of Strategy Instruction Studies to Date}

Evidence from previous research that strategy instruction can lead to shortterm improvement in listening, as measured by pre- and post-tests, is inconclusive. For example, no clear improvement was found in the listening of the Japanese students of EFL involved in Ozeki's (2000) study ${ }^{1}$. Where improvement has been found it has been slight or limited to certain areas of listening only. O'Malley et al. (1985) found differences, but not statistically significant ones, in the gain scores at post-test of three groups of ESL learners who received different amounts and types of strategy instruction. In McGruddy’s (1995) study, significant pre-post test differences in listening achievement (in favor of the intervention group) were found in a nonstandardized listening test used, but not in a standardized test. Similarly, while the 
scores of the intervention group in Seo's (2000) study surpassed those of the control group in the two final tests in a series of eight, learners in the intervention group appeared to improve mainly in their use of bottom-up strategies, with the top-down strategies of 'inferencing' and 'elaboration' (relating new information to prior knowledge) apparently less sensitive to intervention.

By contrast, more success was achieved in two other studies, the first by Thompson and Rubin (1996), the second by Kohler (2002). In the first study, an intervention $(\mathrm{N}=24)$ and comparison group $(\mathrm{N}=12)$ of third-year university learners of Russian completed pre- and post-tests with audio and video materials. The intervention group made significant gains over the comparison students in the video test, but gains were smaller on the audio test. In Kohler's study, 70 'lower achieving' learners of Spanish at a US university received strategy instruction. Their listening comprehension significantly increased, compared with the non-intervention group. There does not, however, appear to have been a pre-test of their listening comprehension, without which it is difficult to justify Kohler's claim of significantly improved comprehension for the intervention group.

Since, to our knowledge, no intervention studies have employed a delayed post-test, the extent to which research to date has demonstrated long-term improvements in subjects' listening is limited. Furthermore, in some studies where more short-term improvement in listening was demonstrated through a post-test, the similarity between the type of tasks used in the strategy instruction and the post-test may have contained bias in favor of the experimental condition. This is the case in McGruddy's (1995) study, where significant pre-post test differences in listening achievement (in favor of the intervention group) were found only in the video test 
designed for the study, and which closely resembled materials used in the instruction, but not in a standardized audio test.

\section{Listening Instruction Models Adopted in Previous Studies}

We have already referred to the theories behind the general approaches adopted in the strategy instruction programmes reviewed. At a practical level programmes have contained similarities and differences in terms of a) which strategies were taught to students and b) the amount of support provided by teachers or researchers during the guided and structured practice phase. However, in terms of how an instruction programme might proceed, most studies have adopted a model which can be summarized thus:

- Consciousness raising, in which students reflect on the nature of learning and on the strategies they use at present;

- Modeling of selected strategies by the teacher;

- Guided and structured practice of the new strategies in the context of normal class activities, with gradually fewer reminders to use appropriate strategies;

- Action planning, goal setting and evaluation, whereby learners identify problem areas, select strategies that might help remedy them and evaluate their success.

(Rubin, Chamot, Harris \& Anderson, N., 2007).

(For an overview of models of strategy instruction, see Dörnyei, 2005).

While all of the studies presented above differed in the number and type of strategies that were included in the instruction, there was some overlap and a general 
tendency to emphasize top-down strategies such as 'prediction' (McGruddy, 1995; Seo, 2000, in the form of 'identifying key terms' through prediction), 'inferencing' (McGruddy, 1995; Ozeki, 2000; Seo, 2000) and 'elaboration' (Seo, 2000). This emphasis on top-down strategies reflects the theoretical conceptualizations of what a good listener does, as discussed above.

Some studies have defined the strategies taught in very broad terms. For example, 'co-operation', 'selective attention' and 'note taking' were part of the strategy instruction implemented by O’Malley et al. (1985), with these last two strategies also featuring in Ozeki's (2000) study, along with 'summarization'. We should pause here to underscore the concern expressed by some authors (e.g. Dörnyei \& Skehan, 2003; Macaro, 2006) regarding the very different conceptualizations of strategies: from the more narrow 'predicting' to the very broad 'note taking' or 'cooperating'--strategies which themselves might involve a number of other strategies. Furthermore, the lack of consistency in the names applied to different strategies, together with the degree of overlap in their definitions, has been criticized by these authors. Lastly, there is very little theoretical explanation in the studies reviewed of how a strategy such as 'note taking' or 'co-operation' might actually develop the skill of listening in the long term. This long-term development is inherent in the features of a strategy cited earlier (Macaro, 2006), with the emphasis on goal-directedness and transferability also suggesting the development of a degree of independence in learners.

Of the two studies reporting some degree of success, what appears to distinguish their instruction programmes is the degree of reflection involved in the strategy application. Thompson and Rubin's (1996) subjects received instruction in 'planning', 'defining goals', 'monitoring', and 'evaluating', alongside a number of 
cognitive strategies. Similarly, Kohler's (2002) students of Spanish were instructed in 'determining their task-related goals', 'identifying what strategies they might use', 'assessing how well the strategies were working', and 'selecting alternative strategies'. While Kohler's study was limited by the absence of a pre-test, it does suggest the potential benefits of placing emphasis on learner reflection about strategy use. It should also be noted that the intervention group reported a clear increase in the perceived value of strategy use--again evidence of reflection. Reflection was also a feature of a small scale study of primary school ESL learners (Goh \& Taib, 2006) which reported some success.

Within the model of strategy instruction outlined above, it is unclear what level of guidance and structured practice (i.e. 'scaffolding') needs to be given by the teacher or researcher. Indeed, the whole issue of scaffolding receives scant attention in the intervention studies reviewed ${ }^{2}$. The level of scaffolding needs to be explored rather than assumed because of the varying nature of the beliefs that individual learners might bring to their strategic behavior. Learners' beliefs about listening will have an influence on their readiness to adopt new strategies or strategy clusters and this in turn will influence the degree of scaffolding they will require. We therefore turn briefly to theories of self-efficacy in learning and learner beliefs in general.

\section{Strategy Instruction and the Development of Self-Efficacy}

Learners' beliefs about their own abilities and competences to accomplish specific tasks are of particular importance. This is often referred to as their sense of agency (Paris \& Winograd, 1990), or self-efficacy beliefs (Bandura, 1993, 1995). Self-efficacy beliefs are thought to influence individuals' choices, effort and level of 
persistence with tasks, as well as their control over and knowledge of effective learner strategies (Yang, 1999). Self-efficacy beliefs themselves are thought to be influenced by learners' attributions (Bandura, 1993), the reasons they give to explain perceived success or lack of it. Learners who attribute the level of their achievement on academic tasks to factors within their control (for example, to effort expended or to strategies employed) are likely to have higher levels of self-efficacy and to be motivated to attempt similar learning tasks again. As they can alter the amount of effort or the type of strategies they use, the possibility of doing better remains. By contrast, learners who attribute their lack of success to factors beyond their control, such as the difficulty of the tasks they are set, or to perceived low ability, are likely to have lower levels of self-efficacy and motivation. Graham (2006) suggests that such attributions may be particularly prevalent for a skill such as listening comprehension, where learners may view the processes involved as relatively uncontrollable.

Scaffolding, as part of the strategy instruction programme therefore, can play a part in increasing learners' sense of personal control, particularly when it takes the form of feedback on strategy use, in which learners' attention is drawn to the link between the strategies they have used and their learning outcomes. Often known as 'attribution retraining', such an approach has been used successfully in L1 contexts (for example, in L1 reading, Borkowski, Carr \& Rellinger, 1990), but less so in L2 studies. At the same time, such feedback should be complemented by other activities that involve learners in evaluating their strategy use themselves, in which they "detect their relative costs, benefits, and ranges of applicability" (Borkowski et al., 1990, p. 57). Learners who identify the benefits of strategy use in this way are more likely to adopt them and transfer them across a range of tasks. 
Arguably, previous studies have achieved mixed success because of insufficient attention paid to the scaffolding of strategy use in the way outlined above in relation to the learner's self-efficacy. Another important reason might be the field's incomplete knowledge of which strategies are the most effective, and for which kind of task, and our imprecise understanding of what strategies are and what they do. The link back from strategy instruction, to theories of listening processes, via listening strategies theory has not always been a clear and seamless one. This is bound up with the tendency outlined earlier to over-emphasize the importance of top-down strategies, an approach which ignores the possibility that successful listeners may be deploying effective top-down strategies because of their greater linguistic knowledge and, therefore, their ability to access relatively automatically much of the incoming speech stream, thus allowing them to successfully 'compensate' via inference.

Moreover, few interventions have focused on giving students the tools to improve their listening in the long term. Yet, one of the aims of strategy instruction is the development of the independent language learner. Furthermore, motivation theories suggest that being in control of one's learning and making positive attributions of success are the states most likely to produce sustained effort. Longitudinal studies are therefore urgently needed, which rather than viewing strategy instruction as a way of simply transmitting the strategies of 'successful' listeners to 'unsuccessful' ones, are grounded in individual listeners' specific needs and strategic behavior.

The Present Study 
In the light of the above literature and with insights from the pre-intervention phase (which will be described below), we decided to incorporate the following features into our study:

1. A strategy instruction programme devised around the specific needs of the population in question, the needs being identified in a preliminary phase (phase 1 below);

2. a strategy instruction programme which incorporated a strong metacognitive element using a variety of instruments including diaries, learner selfevaluations, and researcher feedback on strategy use;

3. a strategy instruction programme which encouraged learners to see connections between the strategies used and learning outcomes and which clearly identified what strategies and clusters of strategies were supposed to achieve, and giving equal prominence to both top-down strategies and textbased strategies;

4. a strategy instruction programme which was linked (via point 3 ) to individual learner self-efficacy, in that learners were encouraged to evaluate the effectiveness of their strategic behavior against future and similar tasks;

5. the inclusion of a delayed post-test or 'follow up test';

6. listening-test types which were not similar to task types used in the instruction programme.

Phase 1: the Pre-Intervention Investigation 
Prior to our intervention (phase 2), we carried out an extensive investigation into the kinds of difficulties students in this population were experiencing using thinkaloud procedures, with a sample of students $(\mathrm{N}=23)$ very similar to those who took part in the intervention. For a fuller account of phase 1 see Graham, Santos and Vanderplank (2008, forthcoming). We found that while many listeners did engage in a form of prediction, before listening to a passage accompanied by multiple-choice questions, this prediction mostly consisted of thinking about individual items of vocabulary that they expected to hear, based on what was indicated by the multiplechoice options, rather than thinking about what they knew about the overall topic of the text and how that might help their listening. They rarely anticipated that what they heard on the tape might not correspond exactly to what was in the multiple-choice options, a feature of weaker listeners according to Tsui and Fullilove (1998).

Once they started listening, many students simply assumed that if they heard a word identified in the preparation phase as likely to occur, then this word must be the correct answer, without stopping to check what was said on either side of this word. That is, very few students monitored their comprehension by combining prediction of what words might occur in the text with a reflection on the immediate linguistic context in which such predicted words occurred. Some made assumptions about the text based almost solely on their prior knowledge, what was likely to be true, rather than listening carefully to the L2. Others made no use of prior knowledge at all when faced with words they did not know or recognize. Students frequently commented that when they listened they focused on 'key words', but their interviews suggested that what they meant by key words was the items of vocabulary that they happened to understand or hear, even though they might or might not represent key ideas in the text. Identifying where one word ended and another started was an additional 
difficulty, as was recognizing familiar words within a stream of French (see also Graham \& Macaro, 2007).

The extensive pre-intervention investigation of the problems encountered and the strategies used by learners at this specific proficiency level led us to decide that strategic input would be most beneficial in the following areas: effective prediction formation, followed by confirming the evidence for predictions made (i.e. a component of monitoring); identifying real key words; inferring the meaning of unknown words; strategies for recognizing familiar words and for recognizing word boundaries in the speech stream.

The use of this cluster of strategies was then individualized through feedback and the learner's own self-evaluations. Thus it was not a question of learners simply deploying one strategy more often but of deploying all the strategies in combination with each other. Returning to our earlier contention, this combining of strategies was encouraged both for 'compensatory purposes' and for 'confirmatory purposes'.

In order to test the effectiveness of our strategy instruction the following research questions were formulated:

1. Can a programme of strategy instruction improve the listening comprehension of lower-intermediate learners of French as a foreign language?

2. Among learners receiving instruction, is the level of scaffolding provided a factor in improvement in listening comprehension?

3. What are the effects of strategy instruction on learners' self-efficacy beliefs for listening comprehension?

Method 
Design

The design was a quasi-experimental, pre-test, post-test (henceforth Time 1 and Time 2) with two intervention groups and one comparison group (CG). Interventions lasted from October 2004 to April 2005, with part follow-up (henceforth Time 3) in October 2005. The interventions groups were: high-scaffolding group (HSG) and low-scaffolding group (LSG). All aspects of the intervention programme were taken from normal class time. The intervention groups received no more tuition time than the comparison group, as ascertained through a questionnaire administered at the end of the study and confirmed by teacher interviews and our observations.

\section{Context and Participants}

The target population was students of French as a foreign language in England. Students were preparing for the Advanced Subsidiary (AS) level examination and were in year 12, the first year of post-compulsory education. Year 12 students are aged 16-17 years, have almost invariably been studying the language for five years, and have elected to continue studying it following national exams at the end of the previous year (known as GCSE). General proficiency levels tend to vary considerably as do the numbers of students in classes. At the end of year 12 students can elect to continue studying the language at 'Advanced Level' in year 13.

The sampling frame for the intervention schools was restricted to two counties in the south of England because of resource limitations. The sampling frame for the comparison schools also came from the South of England but from different counties 
than the intervention schools in order to avoid leakage. In allocating schools to conditions we endeavored to create three groups that were as evenly matched as possible in terms of school type (including location, overall pupil achievement).

Because of school management policies we were not in a position to apply individual randomization as a sampling strategy. Instead we obtained a stratified sample with matched pairs.

This sampling strategy provided us with an initial sample of 151 students (120 females and 31 males - reflecting the same imbalance in this population) from 15 schools for the Time 1 and Time 2 tests. Because of the optional nature of the course for this population, the total number of students who completed tests and surveys at both Times 1 and 2 was reduced to $107(\mathrm{HSG}=29 ; \mathrm{LSG}=39 ; \mathrm{CG}=39)$ and further reduced to 59 at Time 3, i.e. one year after the beginning of the investigation (HSG $=$ $20 ; \mathrm{LSG}=11 ; \mathrm{CG}=28$ ).

We followed the national guidelines on ethical issues (British Educational Research Association) informing participants as to the general nature of the research, guaranteeing anonymity, assuring them that non-participation would not in any way affect their studies or their teachers' opinion of them, and allowing them to withdraw from the project at any time. Only one participant withdrew half way through the project (from an LSG school).

Data Collection Instruments

Listening proficiency tests. 
Participants were tested for listening proficiency at Times 1, 2, and 3 using three different audio-recordings on the same topic. At each time point they listened to the recording, which was controlled by a researcher, and individually wrote what they thought they had understood ('free recall', a method used in other studies, e.g. Chien \& Wei, 1998; Osada, 2001; Vogely, 1995). The listening test was divided into a number of short passages (examples are given in Appendix 1). During the test, participants wrote their responses during two hearings of each passage. The listening tasks were of a similar type and level of difficulty to those used in year 12 teaching materials and to tasks set in the AS level examination.

The level of difficulty of the test was held constant at the three time points, with passages of very similar length, speed and vocabulary difficulty selected. In addition, the level of difficulty of all tests was monitored by asking a similar 'pilot group' of students not involved in the intervention to listen, firstly, to the eight passages (four for each test) used at Time 1 and Time 2, and rate them in terms of difficulty. Students' ratings confirmed that both tests were very closely matched. The same procedure was then followed for Time 3 passages, comparing them with Time 2 passages.

\section{Self-efficacy questionnaire.}

Immediately following the Listening Proficiency Tests at Times 1 and 2, participants were asked to complete a brief questionnaire (see Appendix 2) related to their perceptions of their abilities in listening and particularly asking them how confident they felt about doing similar listening tasks in the future. This questionnaire was based on one used in a study by the National Capital Language Resource Center 
(2000) and was adapted to focus on the listening skills that would be drawn upon in the listening tests and AS examination (see also Graham, 2007).

At Time 2, students in all three groups additionally completed a questionnaire that asked them to assess, amongst other things, how much they felt they had improved in listening (if at all) from October to April, and for the intervention groups, how useful they had found the strategy instruction, with both questions using a scale of 1 to 6,1 being the lowest rating.

\section{The Intervention}

The intervention programme had a number of features common to both the HSG and LSG and three features which the HSG received in addition. The common features were:

1) Strategy lists in listening for students to consult when involved in listening activities in normal class time

2) Materials for raising awareness of bottom-up processes

3) Materials for raising awareness of the speech segmenting patterns of French

4) Materials for encouraging accurate inferencing

5) Materials for encouraging prediction and monitoring strategies

6) Self-evaluation sheets for the learners

In addition the HSG received: awareness-raising of strategy use, a diary in which to comment on their strategy use, and written feedback on their strategy use and on the apparent relationship between their strategy use and success at listening. This 
additional scaffolding was intended to promote higher levels of reflection than in the LSG as well as providing evidence of that reflection.

We provide here further descriptions of how the above features of the intervention relate to our earlier discussion of the strategies research literature.

Strategy lists: All intervention students were constantly reminded of the possible strategies they might use when listening via a strategy tick-list they received from their teacher. They were asked to reflect on these strategies before and after the listening task. The objective here was to continually raise awareness of strategies available without suggesting that there was any one strategy that was superior to others. In addition, students were asked to reflect on which strategies and strategy combinations had been the most useful for each particular task.

Additional awareness-raising and reflection: The HSG students were asked to consider a number of statements about language learning made by other students (the statements were drawn from Graham, 2006). They were asked to identify those statements which indicated that the student was in control of his or her learning and those which indicated a lack of control. After a group discussion in which students considered whether they felt in control of their language learning, researchers gave a presentation on how strategy use can help students achieve this control. This included examples of the listening strategy clusters used by other learners (drawn from Graham, 1997 and from phase 1 data). Students were then asked to discuss these in groups. Following this, a researcher presented, in diagram form, the processes involved in listening and a number of cognitive and metacognitive strategies associated with them. More group discussion ensued.

Materials for raising awareness of bottom-up processes: As outlined above, our phase 1 investigation suggested that students experienced difficulties with the 
perception of words and phrases in French because of the grapheme-phoneme correspondence problems in the language. We therefore encouraged them to 'sound out' and 'visualize' what graphemes strings of sounds might be made up of using a number of techniques. 'Sounding out' and 'visualizing' are strategies which use two of the components available in working memory (the phonological loop and the visual-spatial sketchpad respectively - Baddeley \& Logie, 1999).

Materials for segmenting French speech: Again as a result of the phase 1 investigation, we encouraged students to use a 'segmenting' strategy based on the intonation patterns of French which are very different from English (see Appendix 3). In both this and the above materials we were following the argument that whilst strategy use should be clearly differentiated from knowledge of and about the language, nevertheless strategy deployment may be impossible without that knowledge (Lam \& Wong, 2000; Macaro, 2006).

Materials for encouraging sensible predicting, accurate inferencing, and increased monitoring: Materials (see Appendix 3) were presented to students so that they could correctly infer the meaning of unfamiliar lexical items, phrases or propositions in the text. Prediction and monitoring materials were devised that specifically encouraged listeners to monitor whether their early predictions were in fact substantiated by later in-coming text ( Tsui \& Fullilove, 1998) and where the information was 'passage-dependent' (Chiang \& Dunkel, 1992), i.e. where answers to comprehension questions could only be found in the text itself and not inferred solely from prior knowledge. These materials also aimed to develop strategies for identifying the important elements of a text.

Strategy use diary: The HSG group was provided with a diary in which to record, on four occasions, the progress they felt they were making with listening and 
the part that strategy use might be playing in this. They did so by writing under the key headings: What went well? Why? What didn't go so well? Why? In addition, students were asked to comment on the listening strategies they thought they had used during the month, their plans for developing strategies during the next month. The purpose of these diary headings was to help students to see the connection between strategies used and how well they had completed the listening task, and to encourage reflection about what strategies they might try out in the future to further improve their learning. This diary was not well kept by the students, possibly because of the examination pressures that they were facing. In view of this, researchers just accepted as many diary entries as students felt able to make.

Written feedback: The HSG group received written personalized feedback on each of the stages or processes in their listening and on the strategies they might have used (see Appendix 4). In order to do this, HSG students were required to submit, alongside their work, the tick-lists of strategies that they had used, their evaluations of them, and any diary entries they had made. Feedback on the diary entries sought to underline the connection between strategies and outcomes. When students showed signs of making maladaptive attributions for not doing well on a listening task, perhaps blaming the speed of the recording, the feedback tried to show how a different strategy might help them cope with these problems. We would consider these submissions and their subsequent feedback to be the most important difference between HSG and LSG. However, the number of pieces of feedback each student received was relatively small (a maximum of seven).

\section{Monitoring the Intervention}


In order to ensure that the programme of instruction was indeed the independent variable that might have an effect on the dependent variables (listening comprehension and self-efficacy), we took the following measures. We observed a number of lessons in which strategy instruction was taking place; we delivered parts of the intervention ourselves where teachers felt they lacked confidence to carry out the instruction; we kept copies of tasks carried out, strategy lists completed (and in the case of HSG of feedback given by the researchers) which were related to the intervention; we conducted semi-structured interviews with teachers. These interviews provided further evidence of the level of intervention that the students received (see Lawes \& Santos, 2007).

\section{Analysis}

At each time point, responses to the listening tests were scored by two raters independently, using a banded rating score which assessed the number of idea units recalled, whether these were words or phrases, to give a score per passage for each learner and a total score. Scoring was done blindly at Time 2 and Time 3. Inter-rater reliability was assessed by comparing the scores for each rater at Time 1 and Time 2, per passage and for total scores. At Time 1, correlations for scores on each passage ranged from .86 to .97 and the total scores correlated at .95 . At Time 2, correlations for scores on each passage ranged from .86 to .97 , and the total scores correlated at 96. Differences in scores were then resolved by discussion, at all three time points.

For the self-efficacy questionnaire, the internal consistency of the four items, as measured by Cronbach's alpha, was .86 . Scores for these four items were then combined to give an overall self-efficacy score at Times 1 and 2 . Time 3 data were not 
available for all subjects for self-efficacy. In order that any differences in the various aspects of listening (e.g. for gist, for detail) might also be explored, gain scores were calculated between the two time points for each item of the questionnaire. For each condition, frequencies and percentages were calculated for students making no gain or regressing in their level of self-efficacy, and for students making a gain of $10 \%$ or more.

The alpha level was set at $p=<.05^{3}$. All data were entered into SPSS.

Results

Research Question 1: Can a programme of strategy instruction improve the listening comprehension of lower-intermediate learners of French as a foreign language?

Descriptive statistics were calculated for the listening test scores, at Time 1, Time 2, and Time 3, and these are reported in Table 1. As we can see, at Time 1 the comparison group obtained the higher mean score, whereas at Times 2 and 3 the intervention group (HSG and LSG combined) obtained the higher mean score.

\section{<Table 1 here>}

As scores for the listening test at Time 1 were not normally distributed $\left(\right.$ Kolmogorov-Smirnov $\left.=.133, d f=107, p=.001^{*}\right)$ and therefore did not meet the criteria for parametric tests, a Mann-Whitney-U test was conducted. This showed that the higher mean score for the comparison group was statistically significant: $Z=$ $3.061, p=.002 *$. In order to control for differences in scores at Time 1 , we then carried out an ANCOVA at Time 2, with the Time 1 scores as the co-variate, after 
ensuring that the Time 1 results were significantly correlated with the Time 1 results (Spearman's $r=.62, p=.001 *$ ). ${ }^{4}$ The results show that the advantage of the intervention group over the comparison group was statistically significant: $F(1,104)$ 24.66, $p=001 *$. There was a small effect size: $\eta^{2}=.19$.

In order to assess the long-term effects of the strategy instruction, we carried out a similar procedure for the reduced sample at Time 3 (12 months after Time 1), with Time 1 scores as the covariate for the Time 3 ANCOVA. Once again the higher mean score of the intervention group over the comparison group was statistically significant: $F(1,56) 13.18, p=.001 *$. There was a similar small effect size: $\eta^{2}=.19$.

Research Question 2: Among learners receiving instruction, is the level of scaffolding provided a factor in any improvement in listening comprehension?

We carried out descriptive statistics for the three groups, that is the HSG, the LSG and CG and these are reported in Table 2.

\section{<Table 2 here >}

As can be seen from the descriptive statistics in Table 2, all groups made gains between Time 1 and Time 2, with the CG condition obtaining the highest mean score at Time 1 and the HSG obtaining the highest mean score at Time 2. In order to see whether this apparently greater improvement in listening comprehension for the HSG was statistically significant, we conducted an ANCOVA with Time 1 as the covariate and with 'condition' (HSG, LSG, CG) as the between-groups factor. This gave a significant difference for condition, $F(2,103)=16.95 ; p=.001^{*}$, with a larger effect size than for Research Question 1, partial $\eta^{2}=.25$. Similarly, pairwise comparisons 
showed that at Time 2 there was a significant difference between HSG and LSG ( $p=$ $.001 *)$, a significant difference between LSG and CG $\left(p=.001^{*}\right)$ and a significant difference between HSG and CG $\left(p=.001^{*}\right)$. When the ANCOVA was repeated using an additional initial proficiency measure (GCSE national exam results) as a covariate, a significant main effect for 'condition' remained $\left(\eta^{2}=.28\right)$. Thus even after controlling for initial general proficiency, the level of scaffolding was found to have a significant effect on improvements in listening comprehension.

Finally, to investigate the longer-term effects of the level of scaffolding we carried out an ANCOVA for Time 3 with Time 1 as the covariate and 'condition' as the between groups factor. Again, there was a significant difference for condition, $F$ $(2,55) 10.33, p=.001 *$. Pairwise comparisons showed differences between HSG and $\operatorname{LSG}\left(p=.01^{*}\right)$, between LSG and CG $\left(p=.001^{*}\right)$ and between HSG and CG $(p=$ .03). We should note that LSG outperformed HSG at Time 3, as well as the very considerable attrition rates for all groups. We return to these matters in the discussion.

Research Question 3: What are the effects of strategy instruction on learners' selfefficacy beliefs for listening comprehension?

Descriptive statistics for total self-efficacy scores for the three conditions were calculated at Times 1 and 2 and are shown in Table 3. As subjects were asked to indicate on a scale of 0 to 100 how confident they were about four areas of listening, the maximum score for a subject would be 400 .

\section{<Table 3 here>}


As the scales on the questionnaire were ordinal, the non-parametric KruskalWallis test was used to establish if there was a statistically significant difference between the three conditions at pre-test and we found that there was $\left(\chi^{2}=10.47, d f=\right.$ $2, p=.005)$. In order to control for these differences we therefore carried out an ANCOVA at Time 2, with Time 1 scores as the co-variate, and with 'condition' as the between-groups factor. This gave a significant difference for condition, $F(3,2)=$ $4.58, \mathrm{p}=.01 *$. Pairwise comparisons showed that at Time 2 there was a significant difference between HSG and CG $\left(p=.01^{*}\right)$ and between LSG and CG $\left(p=.01^{*}\right)$. The difference between HSG and LSG was non-significant.

Looking at particular aspects of listening self-efficacy, Table 4 indicates that both the HSG and LSG made greater gains than the CG for each aspect.

\section{$<$ Table 4 here}

A Mann-Whitney-U test showed that HSG and LSG gains were significantly greater for understanding detail and understanding opinions than those of the CG:

Understanding detail: HSG-CG: $Z=-2.74, p=.006^{*} ; \mathrm{LS}-\mathrm{CG}: Z=-3.13, p=.002^{*}$;

Understanding opinions: HSG - CG: $Z=-2.47, p=.01 ;$ LSG - CG: $Z=-2.46, p=$ $.01 *$

No statistically significant difference was found between the HSG and LSG gain scores. 
The above results need to be interpreted cautiously, however. Before the intervention, the HSG had significantly lower levels of self-efficacy for listening than the CG on understanding details and understanding unknown words, which may have influenced the greater gains in self-efficacy for the HSG. Hence the HSG may have made the most gains in self-efficacy partly because of their initial low base.

Students were asked in the final questionnaire to comment on how much they felt their listening had improved during the project. The HSG felt their listening had improved more than the LSG or CG, at a level that approached significance (MannWhitney-U test): HS-CS: $Z=-2.24, p=.02$ ns.; HS-LS: $Z=-1.88, p=.06$ ns.), with no significant difference between LSG and CG.

\section{Discussion}

This study investigated whether strategy instruction was an effective classroom-based practice in raising the level of proficiency in listening comprehension, whether it made learners feel more confident about their listening, and also whether different models of instruction through the level of support given (scaffolding) were important factors in providing desired outcomes.

Overall, the strategy intervention programme had a positive impact on listening performance (Research Question 1). Students who underwent strategy instruction outperformed those who did not and demonstrated that they themselves recognized this improvement. There is some indication, albeit a tentative one because of attrition rates, that this improvement was long-term.

First, we would argue that our more positive results, in relation to previous studies, were obtained by high levels of focus on specific clusters of cognitive 
strategies involved in listening to a second language, and particularly French ('prediction', 'directed attention', 'phonemic segmentation', 'inference', 'verification') in combination with the metacognitive strategies of 'monitoring' and 'evaluating'. Clustering of strategies was the first theoretical underpinning of our intervention programme. We would argue that individual cognitive strategies cannot be considered, and therefore taught, in isolation (as other studies have done). This supports the position of recent strategy theorists (e.g. N.J. Anderson, 2002, 2005; Macaro, 2006). When applied to L2 listening tasks, strategies are all part of a balanced set of tools at the disposal of the listener for him/her to apply effectively according to the demands of the task (or sub-task, as in problem solving a particular section of the input). For example, the strategy of 'inferencing' cannot be taught in isolation from 'verifying' that the inference is correct from other in-text evidence, this needing a momentary confirmatory focus on bottom-up strategies. Indeed we would argue that any L2 listener would be hard put not to infer at some stage while listening to a reasonably challenging L2 text. To therefore isolate and advocate the strategy of 'inferencing' (see Ozeki, 2000, and Seo, 2000) does not make much sense. Inferencing (or at least effective inferencing) comes about as a result of deploying a whole cluster of strategies (in Macaro's 2006 terms of reducing the size of strategies as much as is practicable) in order to overcome lexical difficulties in the text.

The second theoretical underpinning of our intervention programme was to identify specific group (lower-intermediate learners of French) needs and individual learner strategic behavior, and to design strategy instruction accordingly. Whilst this has the disadvantage that our results are perhaps not generalizable beyond this population, we believe that this was the second important aspect that led to a more positive result than other studies. Our results appear to confirm our belief that 
listening strategy instruction should not necessarily be modeled on a notion of a universal successful listener or high proficiency listener. That listener may be using a particular set of strategies because of the level of linguistic knowledge that they have at their disposal rather than having reached a certain level of success or proficiency because of a set of strategies used. Furthermore, learner engagement in the strategy instruction process, in terms of the selection, application and evaluation of strategies, seems to us to be essential for long-term strategy development. This, in our view, can only occur if strategy instruction is learner-centered and (at least at first) task-specific. It is less likely to occur in a model where a notion of a successful language learner is imposed on an individual.

We now turn to the amount of 'scaffolding' needed for the intervention (Research Question 2). Here the picture is slightly less clear. The HSG significantly outperformed the LSG at Time 2 (that is, soon after the end of the intervention). However, the performance was reversed some six months later (Time 3). Similar trends apply to students' self-efficacy for listening, with both the HSG and LSG making significantly greater gains than the $\mathrm{CG}$, but with no significant difference between the two intervention groups. These mixed results are somewhat surprising. We would have expected, from the theory presented earlier, where strategy application and attribution were considered as inseparable, to have obtained more favorable results for the HSG even in the long-term. There are at least two possible reasons for this lack of long term difference in terms of impact of levels of scaffolding.

First, the attrition rate for all groups, but particularly the LSG, was high. The percentage of students who opted to continue with French beyond their AS exam was: HSG: 69\%; LSG, 28.2\%; CG, 71.8\%. It is therefore possible that in year 13 those 
students that remained in the LSG were particularly high achievers in all aspects of French learning, not just listening comprehension.

Second, both LSG and HSG students were asked to reflect on their strategy use at the end of each activity in the programme, to evaluate the effectiveness of the strategies they had used. This perhaps gave the students in the LSG who remained at Time 3 sufficient opportunities to reflect on the connections between the strategies employed and how well they performed on the listening activity. In addition, as was noted earlier, the number of pieces of feedback HSG students received from the researchers was relatively small. A more long-term programme of instruction and feedback may have produced more long-term differences between the two intervention groups.

On the other hand it should be remembered that HSG students reported a greater sense of improvement in their listening at Time 2 than did LSG students. There is thus evidence, albeit tentative, that strategy instruction with feedback that focuses on the link between strategy use and successful listening can have a positive impact on both listening performance and students' self-efficacy for listening, even with a relatively small amount of feedback.

Our third theoretical underpinning was that progress in listening comprehension is closely bound up with altering students' attributions for success and failure (via encouragement to reflect on, modify and re-evaluate one's strategic behavior) and the resulting changes in levels of confidence. Our positive results in listening comprehension appear to be closely linked to changes in self-efficacy (Research Question 3). The self-efficacy gains suggest that the strategy instruction had the biggest impact on intervention students' confidence in understanding 'details' and 'opinions'. We should note that understanding details and opinions often involves 
a constant interaction between bottom-up and top-down strategies and this lends further support to the interactive listening model adopted. Understanding details and opinions therefore suggests that the instruction which targeted identification of both individual problem words and inferencing at a more general level was effective.

A final important feature of the study was a methodological one. We ensured that the testing procedure did not bias the intervention students by implementing a listening-test type which was not practiced during the strategy instruction programme. By doing so, we believe that we also provide evidence that students were able to transfer their strategic behavior from the tasks they engaged in during the instruction to a different task in the listening tests. This evidence of strategy transferability was a feature discussed earlier (Macaro, 2006).

Our study contributes to learner strategy theory in general by exploring the link between strategy use, self-efficacy and attributions. It demonstrates that:

- a strategy can indeed be explained in terms of its goal(s). A goal can be articulated (e.g. 'to improve my segmentation of French oral text') and this can be linked in the learner's mind to improving self-efficacy;

- the mental action that a strategy represents can be identified in relation to and in combination with other mental actions. The strategy cluster deployed in a specific task can be linked in the learner's mind to attributions of success or failure in ways that permit solutions to be found, by the refocusing of the locus of control;

- a strategy's function, in a specific learning situation, and relative to learners of a particular level of proficiency, can be evaluated for its transferability to other learning situations. 


\section{Limitations}

1) Although our monitoring of the intervention (see earlier) provides us with a measure of confidence that the programme was delivered uniformly, the number of classes involved makes it impossible for us to claim categorically that the strategy instruction was delivered in identical fashion (according to scaffolding level) by each teacher when researchers were not present. On the other hand, it was judged important to deliver the instruction in diverse learning environments which reflect the circumstances in which language teaching takes place in England, and this might be seen as a strength of the study rather than a limitation.

2) We did not investigate which specific strategies the students found most useful. Whether this is a limitation or not is open to debate. Our opinion is that to separate strategies from their clusters is inappropriate. However, it might have been possible to develop some kind of instrument which measured the changes in their deployment of strategy clusters over time and against particular listening tasks or subtasks. This may be an avenue for future research, with a clearer focus on the exact nature of successful strategy clusters.

3) We were not able to ascertain whether the intervention had a positive or negative effect on other aspects of the students' performance.

4) We have already mentioned the attrition rate, between the three different time periods. This attrition rate particularly affected our delayed test because of the optional nature of the language course the students were undertaking. This is an inevitable consequence of attempting classroom-based longitudinal interventions.

\section{Conclusions}


Our over-arching aims were to investigate whether intervention via a listening strategy programme was worthwhile with a population of students who appear to find listening at lower-intermediate level one of the most difficult skills and who, past research suggests, appear to lack both the tools and affective disposition to overcome their problems.

We can conclude from the findings that the intervention was, essentially, beneficial both in terms of improving listening proficiency and raising the students' self-efficacy. Hence the present study provides stronger evidence than previous interventions that strategy instruction in listening is beneficial. We attribute the success of the intervention to those elements that differentiate it from previous programmes: the strong link made between strategy deployment and self-efficacy; an increased level of learner engagement with the instruction, through targeted scaffolding; careful selection of strategies, with a precise definition of what each strategy is, what it is meant to achieve, and how it interacts with other strategies in a cluster as related to a specific listening task; and a programme design that addressed the needs of a specific learner population, rather than super-imposing the strategies of 'successful' learners in different contexts, learning different languages, and having achieved different levels of general proficiency. As Kojic-Sabo and Lightbown (1999) comment, we should be careful not to assume "that strategies used by successful learners will undoubtedly be helpful to less successful ones" (p. 190). The value added nature of strategic behavior, over and above more general linguistic knowledge, can only be truly measured within the theoretical model, adopted in this study, of what a strategy is and does, how it operates in a cluster of 
strategies in relation to a task, and how it operates within an individual learner over a period of time.

The question remains as to whether strategy instruction, including a strong element of feedback on strategy use, is a productive approach to take with learners from the very first stages of their language learning. Further research is needed to explore this issue. We believe this type of strategy instruction may offer long-term benefits for learners in terms of their listening performance and beliefs about listening. Moreover, to provide learners with feedback on the process of their learning would match perfectly the 'assessment for learning' programmes that have gained popularity in the general world of education (e.g. Black \& William, 1998). Offering and receiving such feedback, however, takes time and application from both teachers and learners. Whether this additional attention given to the students is feasible and cost-effective remains a question to be answered, and perhaps only by teachers and students themselves. 
Notes

1. Ozeki (2000) claims some success for the intervention. However, a close examination of the results obtained does not support this.

2. While in Seo's (2000) study there is some evidence of scaffolding in the form of reciprocal teaching among students, teacher feedback seems to be more directed towards degree of comprehension rather than towards strategy use.

3. For post-hoc tests involving multiple comparisons, a Bonferroni adjustment was made in order to avoid obtaining significant results by chance because of multiple tests. This was done by dividing the alpha level (.05) by the number of comparisons made (3), adjusting the alpha level to .017 .

4. For each ANCOVA conducted, we ensured that the dependent variable and the covariate were significantly correlated. 


\section{Acknowledgements}

This research was made possible by a grant (no. RES-000-23-0324) from the Economic and Social Research Council, UK. We would like to express thanks to Robert Vanderplank for his help in designing the material for the listening strategy instruction and listening proficiency tests described in this article. Thanks go also to the other members of the research team: Kristyan Spelman Miller, Brian Richards, Denise Santos, Shirley Lawes and Lynn Erler. 
Appendix 1

Listening Tests

NB. For reasons of space one passage only is given from each test. The full versions contained four passages per test. All French passages shown here are from Pillette and Clarke (1999).

\section{Time 1.}

- Bon, alors, que représentent les vacances pour vous?

- Moi, je travaille beaucoup pendant l'année, enfin, j'étudie, je suis étudiant, alors pendant les vacances...

- Vous cherchez...?

- J'ai vraiment besoin de voir quelque chose de complètement différent.

- Faut changer d'air?

-Ah oui, absolument. J'aime changer d'air.

\section{- Complètement.}

(-So, what do holidays mean for you?

- I work a lot during the year, I mean, I study, I'm a student, so during the holidays....

- You're looking for...?

- I really need to experience something completely different.

- You need a change of scene?

- Yes, absolutely. I like to have a change of scene.

- Totally.) 


\section{Time 2}

\section{-Quel genre de vacances est-ce que tu préfères d'ordinaire?}

-Ben, pendant deux ans, l'été, j'ai fait du camping avec des cousins. Ils sont un peu plus vieux que moi alors pour les parents, ça cause pas de problèmes.

\section{-Ça les rassure!}

-Ouais, c'est ça. Quoique, tu sais, on s'ennuie pas, hein! Heureusement que les parents sont pas trop au courant!

\section{(-What type of holiday do you normally prefer?}

- Well, for the past two years I've been camping with my cousins. They're a bit older than me so for my parents, that isn't a problem.

\section{- That reassures them.}

- Yeah, that's right. Although, you know, we don't get bored! Luckily my parents aren't too aware of what's going on!)

\section{Time 3}

\section{-Les vacances, pour vous, c'est quoi?}

- Oh, j'ai passé l'âge du soleil et du bord de mer, alors depuis quelques années je me concentre plus sur l'aspect culturel.

- Vous vous intéresseriez plutôt aux vieilles pierres, alors?

- Oui, si vous voulez. Ça me permet de faire pas mal de découvertes sur 1'histoire de certaines régions. Et puis, j'en profite aussi pour me consacrer aux romans que je n'ai pas eu le temps de lire pendant l'année. 


\section{(-What are holidays for you?}

-Oh, I'm past the age of wanting sun and sea, so for the last few years I've been more focussed on cultural aspects.

- So you'd be more interested in old ruins then?

-Yes, if you like. That allows me to find out a fair bit about the history of some regions. And also, it allows me to devote some time to the novels that I haven't had time to read during the rest of the year.) 
Appendix 2

Self-Efficacy Questionnaire

\section{Listening to French}

You have just heard an AS-type listening passage. You will have to listen to many passages like this in Year 12.

Circle the number on the line below that shows how sure you are that you could listen to a text like the one you have just heard and do the following:

\section{Understand the gist of what you hear.}

$\begin{array}{lllllllllll}0 & 10 & 20 & 30 & 40 & 50 & 60 & 70 & 80 & 90 & 100\end{array}$

$\begin{array}{lllll}\text { Not } & \text { Somewhat } & \text { Fairly } & \text { Very sure } & \text { Completely } \\ \text { sure } & \text { unsure } & \text { sure } & \text { sure }\end{array}$

2. Understand details.

\begin{tabular}{lllllllllll}
0 & 10 & 20 & 30 & 40 & 50 & 60 & 70 & 80 & 90 & 100 \\
\hline
\end{tabular}

$\begin{array}{lllll}\text { Not } & \text { Somewhat } & \text { Fairly } & \text { Very sure } & \text { Completely } \\ \text { sure } & \text { unsure } & \text { sure } & \text { sure }\end{array}$

3. Work out the meaning of unknown or incomprehensible words.

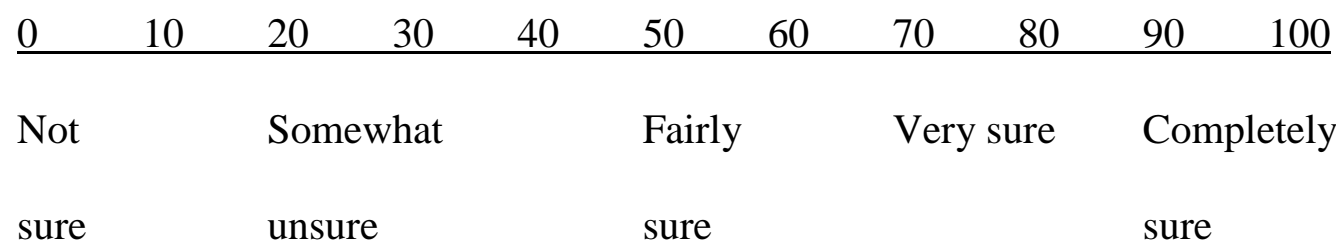

4. Recognise opinions expressed in the text.

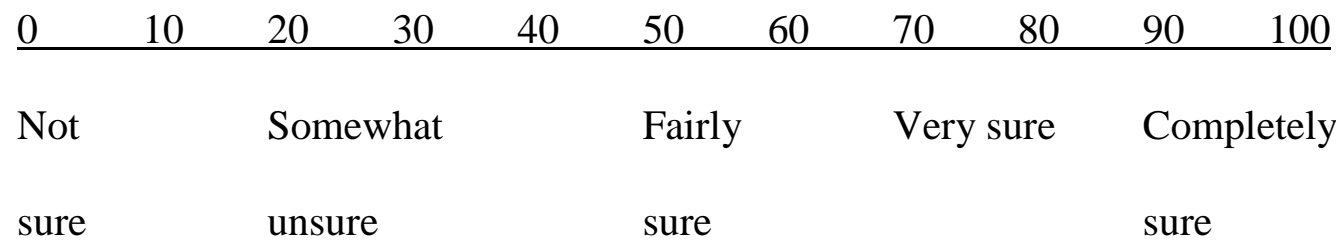


Appendix 3

Selection of Materials Used in the Intervention. (Further examples are available from the authors).

a) Extract from an activity for segmenting words and phrases

1. Listen to the broadcast again. This time the broadcast will have no breaks and there are alternatives phrases or parts of a phrase provided for you to choose. Choose the one which you think best fits what you hear and the context.

1. a. Douze alpinistes

b. Du salpinistes

2. a. ayant été

b. et ont été

c. ayons étaient

3. a. son tombait

b. sont tombées

c. sentombaient

b) Inferencing strategies--understanding new or difficult words (extract).

Students listened to a passage in English which included nonsense words (only the first two paragraphs are reproduced here for reasons of space):

Read as a news report

A Reading man who found lotticks and izzids in his supposedly furbustuous Caribbean hotel was awarded $£ 459$ in damages yesterday by a local magistrate.

Paul Batters paid £1,300 to Atlantic Pacific Tours in March 2000, for a 'furbusty' 
holiday on the island of Martinique...

Students then completed the following activities (extract):

Even when you listen in English, you sometimes need to use strategies to work out the meaning of unknown words. Some of these can be used to help you understand new words in French.

Listen to the passage in English read by your teacher. It contains some nonsense words. Note down what you think they mean and how you worked out the meaning:

1.Lotticks

2.Izzids.

3.Furbustuous

4.Furbusty....

(cont.)

You may have used the following clues:

- Lotticks/izzids experience (direct or indirect) and world knowledge of things one might find in foreign hotels; comparing early and later parts of the passage--'infested' later in the passage confirms that 'lotticks' and 'izzids' are something not very pleasant!

- Furbustuous experience (direct or indirect) and world knowledge of what hotels in the Caribbean are meant to be like; surrounding words/local context/contrast clues ('supposedly'); the rest of the passage tells us the hotel was unpleasant, so 'furbustous' must fit in with this--it was unpleasant, but was supposed to be.....(what would fit?); knowledge of grammar/ sentence structure- 'furbustuous' comes before the noun 'holiday', so must be an adjective; its ending '-uous' is found with adjectives in English (e.g. 'industrious')

- Furbusty context (global)--the passage as a whole--the company promised a hotel which was the opposite of what the man got; 


\begin{abstract}
knowledge of word families--we can tell that it must mean
something similar to 'furbustuous'; knowledge of

grammar/sentence structure--it stands before the noun

'hotel' so must be an adjective, and its ending '- $y$ ' is one that is

used in English for adjectives (cf. 'pretty', 'dirty', etc.)
\end{abstract}

Follow-up task: Students listened to a text about flat-sharing, containing many new or difficult items of vocabulary. They were asked to list the advantages and disadvantages discussed in relation to flat-sharing, and to indicate which strategies they had used, and which were most useful, from:

- local or global context

- own experience, world knowledge

- listening to what comes later in the passage

- 'contrast clues' (often introduced by 'marker' phrases)

- knowledge of grammar and sentence structure

- knowledge of word families

- repetition and paraphrase (sometimes with restatement clues)

- cognates

- checking that the interpretation makes sense 
Appendix 4

Example of Scaffolding Feedback

\section{Feedback to Student F:}

The feedback emphasises that it is the student's strategy use that has led to her progress. Suggestions are then made regarding further strategies to try:

Thank you for writing some interesting comments. It's good to hear that you think you have progressed overall in listening. It seems to me, looking at your work over the past few months, that you have made progress--well done.

Some of the strategies you list as using are helping with this progress--thinking of synonyms for what you might hear is important, as you say, as is making use of how the speaker says things in different ways.

When the passage seems fast and fuzzy, try to use some of the strategies we have used to do with intonation--can you try to see where the stress is in the passage, where the speaker has a little pause at the end of sense groupings?

You say that you will try to listen out for a phrase at a time-- this can be helpful, but don't forget to also take into account what comes before or after the phrase, and don't lose sight of the overall meaning of the passage.

Well done--I look forward to reading your next diary entry. 


\section{$\underline{\text { References }}$}

Anderson, J. R. (1983). The architecture of cognition. Cambridge, Mass.: Harvard University Press.

Anderson, J. R. (1995). Cognitive psychology and its implications, 2nd Edition. New York: Freeman.

Anderson, N.J. (1991). Individual differences in strategy use in second language reading and testing. The Modern Language Journal, 75, 460-472.

Anderson, N. J. (2002). The role of metacognition in second/foreign language teaching and learning. (Retrieved June 2007, from http://www.cal.org/resources/digest/0110anderson.html).

Anderson, N. J. (2005). L2 strategy research. In E. Hinkel (Ed.), Handbook in second language teaching and learning (pp. 757-772). Mahwah, NJ: Lawrence Erlbaum Associates.

Anderson, A., \& Lynch, T. (1988). Listening. Oxford: Oxford University Press.

Arnold, J. (2000). Seeing through listening comprehension exam anxiety. TESOL Quarterly 34, 777-786. 
Baddeley, A.D., \& Logie, R.H. (1999). Working memory: The multiple component model. In A. Miyake \& P. Shah (Eds.), Models of working memory: Mechanisms of active maintenance and executive control (pp.28-61). Cambridge: Cambridge University Press.

Bandura, A. (1993). Perceived self-efficacy in cognitive development and functioning. Educational Psychologist, 28, 117-148.

Bandura, A. (1995). Exercise of personal and collective efficacy in changing societies. In: A. Bandura (Ed.), Self-efficacy in changing societies (pp. 1-45). Cambridge: Cambridge University Press.

Black, P., \& William, D. (1998). Inside the black box: Raising standards through classroom assessment. London: King's College, School of Education.

Borkowski, J.G., Carr, M., \& Rellinger, E. (1990). Self-regulated cognition: Interdependence of metacognition, attributions, and self-esteem. In: B.F Jones \& L. Idol (Eds.), Dimensions of thinking and cognitive instruction (pp. 53-92). Hillsdale, NJ: Erlbaum.

Buck, G. (2001). Assessing listening. Cambridge: Cambridge University Press.

Chiang, C.S., \& Dunkel, P. (1992). The effect of speech modification, prior knowledge and listening proficiency on EFL lecture learning. TESOL Quarterly, 26, 345-374. 
Chien, C., \& Wei, L. (1998). The strategy use in listening comprehension for EFL learners in Taiwan. RELC Journal, 29, 66-91.

Dörnyei, Z. (2005). The psychology of the language learner. Mahwah, NJ: Erlbaum.

Dörnyei, Z., \& Skehan, P. (2003). Individual differences in second language learning. In C. J. Doughty \& M. H. Long (Eds.), The handbook of second language acquisition (pp. 589-630). Oxford: Blackwell.

Field, J. (2004). An insight into listeners' problems: Too much bottom-up or too much top-down? System, 32, 363-377.

Goh, C.C.M. (1998). How ESL learners with different listening abilities use comprehension strategies and tactics. Language Teaching Research, 2, 124-147.

Goh, C.C.M. (2002). Exploring listening comprehension tactics and their interaction patterns. System, 30, 185-206.

Goh, C.C.M., \& Taib, Y. (2006). Metacognitive instruction in listening for young learners. ELT Journal, 60, 222-232.

Graham, S. (1997). Effective language learning. Positive strategies for advanced level language learning. Clevedon, UK: Multilingual Matters Ltd. 
Graham, S. (2002). Experiences of learning French: A snapshot at Years 11, 12 and 13. Language Learning Journal, 25, 15-20.

Graham, S. (2006). Listening comprehension: The learners' perspective. System, 34, $165-182$.

Graham, S. (2007). Learner strategies and self-efficacy: Making the connection. Language Learning Journal, 35, 81-93.

Graham, S., \& Macaro, E. (2007). Designing Year 12 strategy training in listening and writing: From theory to practice. Language Learning Journal, 35, 153-173.

Graham, S., Santos, D., \& Vanderplank, R. (2008, forthcoming). Listening comprehension and strategy use: A longitudinal exploration. System.

Hasan, A. S. (2000). Learners' perceptions of listening comprehension problems. Language, Culture and Curriculum, 13, 137-153.

Kohler, B. D. (2002). The effects of metacognitive language learning strategy training on lower-achieving second language learners. Unpublished doctorial dissertation, Brigham Young University, USA.

Kojic-Sabo, I., \& Lightbown, P. M. (1999). Students' approaches to vocabulary learning and their relationship to success. The Modern Language Journal, 83, 176192. 
Lam, W., \& Wong, J. (2000). The effects of strategy training on developing discussion skills in an ESL classroom. ELT Journal, 54, 245-255.

Lawes, S., \& Santos, D. (2007). Teaching learning strategies: what do teachers learn? Language Learning Journal, 35, 221-237.

Macaro, E. (2006). Strategies for language learning and for language use: Revising the theoretical framework. The Modern Language Journal, 90, 320-337.

Macaro, E., Graham, S., \& Vanderplank, R. (2007). A review of listening strategies: focus on sources of knowledge and on success. In: A.D. Cohen \& E. Macaro (Eds.), Language Learner Strategies: 30 Years of Research and Practice (pp. 165-185). Oxford: Oxford University Press.

Macaro, E., Vanderplank, R., \& Graham, S. (2005). A systematic review of the role of prior knowledge in unidirectional listening comprehension. In: Research Evidence in Education Library. London: EPPI-Centre, Social Science Research Unit, Institute of Education, University of London.

McClelland, J.L., \& Rumelhart, D.E. (1986). (Eds.) Parallel distributed processing: Explorations in the microstructure of cognition. Cambridge, Mass: MIT Press. 
McGruddy, R.(1995). The effect of listening comprehension strategy training with advanced level ESL students. Unpublished doctoral dissertation, Georgetown University: Washington, DC, USA.

Naiman, N., Fröhlich, M., Stern, H.H., \& Todesco, A. (1978). The good language learner. Toronto: Ontario Institute for Studies in Education.

National Capital Language Resource Center. (2000). High school foreign language students' perceptions of language learning strategies use and self-efficacy. Department of Education,Washington, DC.

O'Malley, J.M., Chamot, A.U., \& Küpper, L. (1989). Listening comprehension strategies in second language acquisition. Applied Linguistics, 10, 418-437.

O’Malley, J.M., Chamot, A.U., Stewner-Manzaneres, G., Russo, R.P., \& Küpper, L. (1985). Learning strategy application with students of English as a second language. TESOL Quarterly 19, 557-584.

Osada, N. (2001). What strategy do less proficient learners employ in listening comprehension?: A reappraisal of bottom-up and top-down processing. Pan-Pacific Association of Applied Linguistics, 5, 73-90. 
Ozeki, N. (2000). Listening strategy instruction for female EFL college students in Japan. Unpublished doctorial dissertation, Indiana University of Pennsylvania, The Graduate School and Research Department of English.

Paris, S. G., \& Winograd, P. (1990). How metacognition can promote academic learning and instruction. In: B.F Jones \& L. Idol (Eds.), Dimensions of thinking and cognitive instruction (pp. 15-51). Hillsdale, NJ: Erlbaum.

Pillette, M., \& Clarke, B. (1999). Objectif Bac 1. London: Collins Educational.

Richards, J.C. (1983). Listening comprehension: Approach, design, and procedure. TESOL Quarterly, 17, 219-240.

Rubin, J. (1975). What the 'good language learner' can teach us. TESOL Quarterly, 9, 41-51.

Rubin, J., Chamot, A.U., Harris, V., \& Anderson, N.J. (2007). Intervening in the use of strategies. In: A.D. Cohen \& E. Macaro (Eds.), Language Learner Strategies: 30 Years of Research and Practice (pp. 141-160). Oxford: Oxford University Press.

Rumelhart, D.E. (1980). Schemata: The blocks of cognition. In R. Spiro, B. Bruce, \& W. Brewer (Eds.), Theoretical issues in reading comprehension (pp. 33-58). Mahwah, NJ: Erlbaum. 
Seo, K. (2000). Intervening in tertiary students' strategic listening in Japanese as a foreign language. Unpublished doctorial dissertation, Griffith University, Australia.

Takeuchi, O. (2003). What can we learn from good language learners?: A qualitative study in the Japanese foreign language context. System, 31, 313-432.

Thompson, I., \& Rubin, J. (1996). Can strategy instruction improve listening comprehension? Foreign Language Annals, 29, 331-342.

Tsui, A. B., \& Fullilove, J. (1998). Bottom-up or top-down processing as a discriminator of L2 listening performance. Applied Linguistics, 19, 432-451.

Vandergrift, L. (1998). Successful and less successful listeners in French: what are the differences? The French Review, 71, 370-395.

Vandergrift, L. (2003). Orchestrating strategy use: Toward a model of the skilled second language listener. Language Learning, 53(3), 463-496.

Vann, R.J., \& Abraham, R.G. (1990). Strategies of unsuccessful language learners. TESOL Quarterly, 24, 177-198.

Vogely, A. (1995). Perceived strategy use during performance on three authentic listening comprehension tasks. Modern Language Journal, 79, 41-56.

Wenden, A. (1998). Metacognitive knowledge and language learning. Applied Linguistics, 19, 515-537. 
Yang, N-D. (1999). The relationship between EFL learners' beliefs and learning strategy use. System, 27, 515-535.

Young, M-Y. C. (1996). Listening comprehension strategies used by university level Chinese students learning English as a second language. Unpublished doctoral dissertation, University of Essex. 
Table 1

Descriptive statistics for the three listening comprehension tests (HSG and LSG combined)

Time $1(\underline{\mathrm{N}}=107)$
Time $2(\underline{\mathrm{N}}=107)$

Mean SD Range Max. $\underline{n}$
Time $3(\underline{N}=59)$

\begin{tabular}{|c|c|c|c|c|c|c|c|c|c|c|c|c|c|c|c|}
\hline Condition & Mean & SD & Range & Max. & $\underline{\mathrm{n}}$ & Mean & SD & Range & Max. & $\underline{\mathrm{n}}$ & Mean & $\mathrm{SD}$ & Range & Max. & $\underline{\mathrm{n}}$ \\
\hline Intervention & 16.877 & 7.22 & 39 & 42 & 68 & 29.34 & 10.99 & 50 & 61 & 68 & 29.61 & 8.75 & 34 & 53 & 31 \\
\hline Comparison & 21.51 & 8.11 & 32 & 44 & 39 & 26.69 & 10.02 & 40 & 53 & 39 & 27.42 & 9.04 & 36 & 52 & 28 \\
\hline Total & 18.56 & 7.84 & 41 & 44 & 107 & 28.37 & 10.68 & 50 & 61 & 107 & 28.57 & 8.88 & 37 & 53 & 59 \\
\hline
\end{tabular}


Table 2

Descriptive statistics for the three listening comprehension tests (with HSG and LSG separated).

Time $1(\underline{\mathrm{N}}=107) \quad$ Time $2(\underline{\mathrm{N}}=107) \quad$ Time $3(\underline{\mathrm{N}}=59)$

\begin{tabular}{|c|c|c|c|c|c|c|c|c|c|c|c|c|c|c|c|}
\hline Condition & Mean & SD & Range & Max. & $\underline{\mathrm{n}}$ & Mean & SD & Range & Max. & $\underline{\mathrm{n}}$ & Mean & SD & Range & Max. & $\underline{\mathrm{n}}$ \\
\hline HSG & 16.52 & 6.21 & 25 & 28 & 29 & 31.69 & 9.24 & 36 & 50 & 29 & 26.70 & 7.14 & 24 & 43 & 20 \\
\hline LSG & 17.13 & 7.96 & 35 & 42 & 39 & 27.59 & 11.95 & 50 & 61 & 39 & 34.91 & 9.23 & 29 & 53 & 11 \\
\hline Comparison & 21.51 & 8.11 & 32 & 44 & 39 & 26.69 & 10.02 & 40 & 53 & 39 & 27.42 & 9.04 & 36 & 52 & 28 \\
\hline Total & 18.56 & 7.84 & 41 & 44 & 107 & 28.37 & 10.68 & 50 & 61 & 107 & 28.57 & 8.88 & 37 & 53 & 59 \\
\hline
\end{tabular}


Table 3

Descriptive statistics for the self-efficacy questionnaire

Time $1(\underline{N}=107)$

Time $2(\underline{N}=107)$

\begin{tabular}{|c|c|c|c|c|c|c|c|c|}
\hline Condition & Median & Range & Max. & $\underline{\mathrm{n}}$ & Median & Range & Max. & $\underline{\mathrm{n}}$ \\
\hline$\overline{\mathrm{HSG}}$ & 150 & 190 & 260 & 29 & 210 & 280 & 340 & 29 \\
\hline LSG & 170 & 320 & 370 & 39 & 220 & 230 & 360 & 39 \\
\hline Comparison & 190 & 320 & 400 & 39 & 200 & 305 & 390 & 39 \\
\hline Total & 170 & 350 & 400 & 107 & 220 & 330 & 390 & 107 \\
\hline
\end{tabular}


Table 4.

Descriptive statistics for self-efficacy gains in the four areas, Time 1 to Time 2

\begin{tabular}{|c|c|c|c|c|c|c|c|c|c|}
\hline & \multicolumn{3}{|c|}{$\begin{array}{l}\text { High-Scaffolding Group } \\
\qquad(\underline{\mathrm{N}}=29)\end{array}$} & \multicolumn{2}{|c|}{$\begin{array}{l}\text { Low-Scaffolding Group } \\
\qquad(\underline{\mathrm{N}}=39)\end{array}$} & \multicolumn{4}{|c|}{$\begin{array}{l}\text { Comparison Group } \\
\qquad(\underline{\mathrm{N}}=39)\end{array}$} \\
\hline & $\begin{array}{l}\text { No gain/ } \\
\text { regression* }\end{array}$ & $\begin{array}{l}\text { Gain of } \\
10 \% \text { or more }\end{array}$ & $\begin{array}{l}\text { Median } \\
\text { gain }\end{array}$ & $\begin{array}{l}\text { No gain/ } \\
\text { regression }\end{array}$ & $\begin{array}{l}\text { Gain of } \\
10 \% \text { or more }\end{array}$ & $\begin{array}{l}\text { Median } \\
\text { gain }\end{array}$ & $\begin{array}{l}\text { No gain/ } \\
\text { regression }\end{array}$ & $\begin{array}{l}\text { Gain of } \\
10 \% \text { or more }\end{array}$ & $\begin{array}{l}\text { Median } \\
\text { gain }\end{array}$ \\
\hline Gist & $9(31 \%)$ & $20(69 \%)$ & 20 & $11(28 \%)$ & $28(72 \%)$ & 10 & $18(46 \%)$ & $21(54 \%)$ & 10 \\
\hline Details & $8(28 \%)$ & $21(72 \%)$ & 10 & $12(31 \%)$ & $27(69 \%)$ & 20 & $21(54 \%)$ & $18(46 \%)$ & 0 \\
\hline $\begin{array}{l}\text { Unknown } \\
\text { words }\end{array}$ & $9(31 \%)$ & $20(69 \%)$ & 20 & $11(28 \%)$ & $28(72 \%)$ & 10 & $17(44 \%)$ & $22(56 \%)$ & 10 \\
\hline Opinions & $11(38 \%)$ & $18(62 \%)$ & 10 & $14(36 \%)$ & $25(64 \%)$ & 10 & $20(51 \%)$ & $19(49 \%)$ & 0 \\
\hline
\end{tabular}

Note: * Frequencies for students making a zero gain, and those making a less than zero gain, were combined. 
